FELICITY COLMAN

\section{the power of}

memory

\begin{tabular}{|c|}
\hline $\begin{array}{l}\text { ANNETTE KUHN AND KIRSTEN EMIKO } \\
\text { MCALLISTER (EDS) }\end{array}$ \\
\hline Locating Memory: Photographic Acts \\
\hline $\begin{array}{l}\text { Berghahn Books, New York and Oxford, } \\
2006\end{array}$ \\
\hline ISBN 9781845452278 \\
\hline RRP \$39.95 (pb) \\
\hline
\end{tabular}

Memory is something that brings itself to cultural attention at moments of change, of disjuncture, of fear or loss, and also at times of longing, or achievement, of pleasure and love. As a neurological process that results in an affective range of emotions, from joy to sadness, memory is a powerful force for the growth and dispersal of communities. As a cultural process, the singular realms of the physiologies of memory are managed-tacitly and directly-to provide a system accessible for other participants interested in accessing this temporally metered force. However, cultural management is inextricably tied to political strategy at all levels of governance, so the practices of exhuming and examining the material remnants of bio-communally produced memory through specific cultural markers does not so much provide a history of what memory is, as result in the situation of an often rhetorical practice of a very complex dimension. Can memory be used for reasons other than rhetorical comfort or rhetorical pain? (I recognise my genetic heritage in this or that image/ we are a nation of sportsmen/ you remind me of better times). Can cultural memories be engaged as anything but consensual communal laws? (Ghosts of the civil dead/ this monument is for the dead explorers/ this is a sacred site). Whose memory is it that cultures draw upon for elements of their material functionality?

The essays collected in this volume go a long way toward addressing such difficult questions, first, by locating the situation of photographic documents in communities, and second, by exploring (with various degrees of success) the (often rhetorical) cultural placement of 'memory' 
within and by those sites. Ten chapters and an brought a particular methodology of 'memory introductory chapter by the co-editors, Annette work' into visual and screen studies through Kuhn and Kirsten Emiko McAllister, offer a her work, including the books Family Secrets: breadth of methodologies with which to criti- Acts of Memory and Imagination and An Everycally examine the degrees of rhetorical opacity day Magic: Cinema and Cultural Memory. ${ }^{2}$ In of memory that photography of all types pro- these works, Professor Kuhn highlights the duces. Photography forms an invaluable part of larger, cultural-historical implications for an material culture, necessary for the proper psy- individual or vernacular 'memory' condition chological functioning of societal groups. As and recording process. This important work is such, this volume can be considered alongside reflected through the choices of contributions other recent revisionist accounts of the material made for Locating Memory. In particular, the importance of art forms of all types as cultural discursive style of each of the chapters highrecords for people, such as Robert Bevan's The lights the value of attention to oral histories. Destruction of Memory: Architecture at War or Standard academic word-dress tends to iron Toby Haggith and Joanna Newman (eds), Holo- out class, gender and genetic specific discursive caust and the Moving Image: Representations in tones, and because the situation of the artefact Film and Television since 1933. ${ }^{1}$ At this present is here regarded with equal importance to the time of the culturally extreme poles of poverty form of cultural memory it encapsulates, the and wealth, militarised instability and economic discursive tone of each author provides a critilargesse, the scholarship of these books pro- cal aesthetic wedge with which to engage in the vides a crucial benchmark for research and diverse materials of each chapter. There is a thinking. The present world-ranging conflicts decisive political bite to most of the writing, as of economically fuelled ethnic violence are handling of memory is necessarily fraught with illuminated by these complex accounts of the politically determined subjective qualities, which past; that is, as it is viewed by the present day. today, more so than ever, are determined under And the past is overfull with memories. For the the commodifying gaze of representation.

volume under review, Locating Memory, I found What is memory anyway? Some subjective it difficult to read more than a single chapter at marker of a particular temporal site? If the any one sitting, due to the dense and psycho- notion of memory is primarily concerned with logically taxing nature of the material. Memories the idea of a retrieval of something, the mental are difficult things to deal with.

faculty of recollection, then where exactly is it

Locating Memory was developed from a sym- that memory resides? The book is organised posium (of the same title) held at the Institute into three sections to address this problem: for Cultural Research at Lancaster University in identity, dislocation, reframing. In questioning the UK, where co-editor Annette Kuhn was the location of memory then, via these three Professor of Film Studies. Professor Kuhn has expansive and intensive sites and non-sites, the 
authors in this collection of essays all com- reflexive awareness of the complex issues of mence their search for memory in specific representation, the experience of the situation places. They look at the history behind singular of one's physical prowess of critical viewing photographs made famous by the mechanisms (such as the guided viewing of art in a museum of media's manipulative repetitious histories, spaces) accordingly stimulates the control photo albums, museum deposits, specific mechanisms of that very animation of intellect exhibitions and artworks by artists in specific (in this case, being at the site of a decidedly locations artworks. What quickly emerges is colonialist simulacrum of European signifiers of that text, images and sounds are not the sites 'culture'). Quick reminds himself of Bataille's where memory resides, locked down into some discussion of the museum as a mirror site, safe hold for the convenient retrieval of the reflective of whatever conceptual person one authorial owners or genetic heirs. Rather, it is wants to see. Quick writes, 'Of course, I was place which reconfigures the material object, mistaken in thinking that this space could offer and, in doing so, can affix what is otherwise me some sort of stability, a place in which I ephemeral material to any cultural history might order myself, put myself back together, a eager to build an evidentially based history place to properly be; since, as Bataille indicates, for itself. But as the authors of the volume the very practices of mirroring are themselves demonstrate, any knowledge of the past is as much founded upon excess, 'the ecstasy', as firmly filtered through the conceptual abilities creating it'. (156) Quick's essay draws our of the present. attention to the problems of the construction of

These abilities extend beyond those of the a national identity based upon memories that type discussed in Frances A. Yates's great book have been transported and transposed.

on The Art of Memory, which has always been a

This is also a question that other authors touchstone for the arena of memory study. ${ }^{3}$ For take up, such as Kirsten Emiko McAllister's example, in his chapter 'The Space Between: chapter, 'A Story of Escape', which examines Photography and the Time of Forgetting in the legacy of the internment during World War the Work of Willie Doherty', Andrew Quick II in Canada of people of Japanese ethnic origin describes his encounter with the work of Irish (with similar practices happening over the artist Willie Doherty in a show of 'British' art in world-in the United States and in Australia one of Britain's last, great colonial cities- for example). McAllister grapples with the Sydney, Australia (a place indeed, where the racist national history that decreed parts of her banknotes 'were washable but could not be family be incarcerated in camps for four of the folded' [155]). Just as Yates's work reminds us war years and that is also in governance of her of the centrality for classical thinking of the present day self. Although for this task of an mnemonically sited method for recollection emotionally taxing retrieval, she tells us she has through the physical attachment of things to partaken only of a 'watery coffee from the local places, Quick points out how even with a 7-Eleven' (83), McAllister carefully looks through 
photographic albums held in the Canadian Malcolm Browne's photograph of the immoNational Archive and Museum and describes lation of the Buddhist monk, Thich Quang Duc the material details of many of the photo- in 1963; Eddie Adams's capture of General graphic portraits of families we know are now Loan's execution of a Viet Cong suspect in perhaps dispersed, or dead. Like many of the 1968. Hagopian retrieves the historical situessays in the volume, the Barthesian prick of ation of the actual occasions on which these chronos is never far away. Notwithstanding that photographs were made, citing the political cirmany of the essays are undoubtedly motivated cumstances, as well as the photographers' by quests for individual memory for their reasons for being non-interventionary witnesses authors, they remain bound to their pro- to incredible conditions of violence. Hagopian fessional reflexivity. Perception of the dimen- usefully asks a number of questions concerning sions of evidential reality, of the consciousness media involvement with the release and circuof 'your real self' and that of others engages the lation of images of such events during wartime. aesthetics of memory as a temporal strategy. Hagopian reminds us that like the images of Marianne Hirsch and Leo Spitzer's chapter, abuse at the prison on Abu Ghraib that were 'There Was Never a Camp Here', engages this released in 2004 (although the prison was built transformative aesthetic in their search for the in 1960, and Amnesty International reports forgotten cemetery of Transnistria in Romania, describe the severity and extent of the exepieced together through the memory sites of cution of political prisoners held there, particufilm, woodcuts and drawings, literature. It is larly in the 1980s and 1990s), war atrocities the authors themselves who take photographs proliferate but it is often not until images of to 'perform' and record the site as a locatable these events are circulated that forms of intermemory, enabled as a 'memorial site' through vention take place.

the activity of photography. (152)

There are many further chapters worth

Extending the complementarity the indi- investigating in this volume, delivering as it vidual searches for in terms of the reasons for does a specific methodological clout for the locating memory, larger events that dominate study of memory and its mutations over time collective cultural memories are also addressed which result in national deliriums, amnesias in terms of their functionality. Patrick Hagopian's and all types of cultural disorders.

chapter on 'Vietnam War Photography as a

Locus of Memory' examines a number of the

most commonly circulated images of war, FELICITY COLMAN is lecturer in Screen Studies in including: Nick Ut's photograph of Kim Phuc the School of Culture and Communication running naked down a highway after a napalm at the University of Melbourne. She is the costrike in 1972; Ron Haeberle's 1969 snap of a editor (with Barbara Bolt, Graham Jones and terrified huddle of women and children civilians Ashley Woodward) of Sensorium: Art-Aestheticsseconds before they were murdered at My Lai; Philosophy (2007). She is also the co-editor (with 
C.J. Stivale) of 'Creativity \& Philosophy', special issue of Angelaki: Journal of the Theoretical Humanities, April 2006.<fcolman@unimelb.edu.au>

1. Robert Bevan, The Destruction of Memory: Architecture at War, Reaktion Books, London, 2006; Toby Haggith and Joanna Newman (eds), Holocaust and the Moving Image: Representations in Film and Television since 1933, Wallflower Press, London, 2005.

2. Annette Kuhn, Family Secrets: Acts of Memory and Imagination, Verso, London, 2002 and An Everyday Magic: Cinema and Cultural Memory, I.B. Tauris, London, 2002.

3. Frances Amelia Yates, The Art of Memory, Penguin, Harmondsworth, 1969. 